\title{
Mechanical and Surface Properties of Lignocellulosic Fibres Reinforced Composites
}

\author{
Mariana Domnica Stanciu1,* - Adriana Savin² - Silviu Marian Nastac ${ }^{3}$ \\ 1Transilvania University of Brasov, Department of Mechanical Engineering, Romania \\ ${ }^{2}$ National Institute of Research and Development for Technical Physics, Nondestructive Testing Department, Romania \\ ${ }^{3}$ 'Dunarea de Jos' University of Galati, Engineering and Agronomy Faculty, Romania
}

The aim of this paper is to evaluate the mechanical and surface properties of lignosellulosic fibres reinforced composite before and after photo-degradation exposure. This leads to decrease the mechanical properties of composite as modification of hydrophobic behavior of matrix. In the study, the lignocelluloses specimens were obtained by mix polyester resin type 440- M888 POLYLITE, in a volume percentage of $25 \%$, with different wood particles classified by size classes. The samples were exposed to UV-A radiations with a wavelength $\lambda$ of $365 \mathrm{~nm}$ for 168 hours ( 7 days). The evaluation of the surface energy was carried out by the $\theta$ contact angle method. For mechanical properties, the dynamic mechanical analysis (DMA) was used to determine the variation of storage and loss modulus. The results showed that UV radiation induced structural morphological instability, which leads to hydrophilic effect. The loss modulus recorded an increasing with increases of wood particles sizes.

Keywords: lignocelluloses composite, storage modulus, loss modulus, surface energy, contact angle method

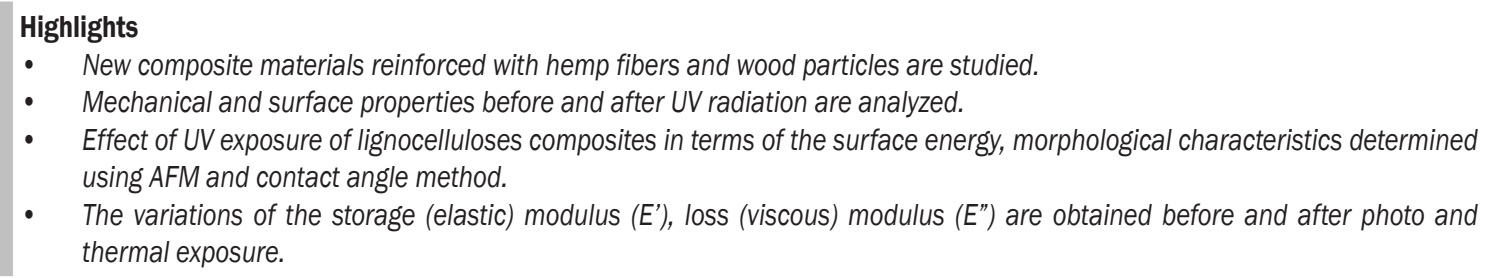

\section{INTRODUCTION}

The advantages and disadvantages of natural fibers as hemp, sisal, jute, wood, and flax have been studied in terms of mechanical properties, durability, cohesion between filler and matrix. The development of natural fiber reinforced biodegradable polymer composites promotes the use of environmentally friendly materials [1]. The new materials derived from biodegradable renewable sources are considered as partial solution to environmental pollution caused by the large volume of waste [2]. Even though the fiber determines the mechanical properties like elastic modulus or strength, the matrix provides the physical and chemical durability by protecting the fiber from environmental influences [3]. The use of lignocelluloses composite with polymer matrix in the environment with UV radiation can cause photodegradation which lead to a weakening of the material and micro-cracking of the matrix [4] and [5]. Photodegradation is the main effect of UV environmental radiation on polymeric materials, which is shown by the following phenomena: breaking chemical bonds between the polymer chains, which leads to the formation of free radicals by dissociating $\mathrm{C}-\mathrm{H}$ bonds from the polymer chains and to the oxidation of its surface because of peroxide radicals [6]. In addition, exposure to UV radiation can make the material more sensitive to the action of other factors (i.e. humidity) [7]. The hydrophilicity is one great drawback when using lignocelluloses fibers as reinforcement in polymer composites. Many approaches studied the tendency of interfacial strength and dimensional stability of bio-composite as results of UV action [8] and [9].

The paper is focused on the photo-degradation mechanism, which influences the surface energy of the lignocelluloses composite. The evaluation of the surface energy of the composite lignocelluloses materials was carried out by the $\theta$ contact angle method identifying the hydrophilic/hydrophobic properties of them. Because of the poor interfacial adhesion between fibers and polymers which leads to limitation of natural fibers reinforcement, Azwa et al. [10] studied the improvement of composite behavior due to addition of coupling agent.

The effect of the oak particle size on the mechanical and morphological properties has been studied [6]. Mechanical properties of wood plastic composites (WPC), determined by tensile and 
bending tests show an increase of elasticity modulus $E$ and yield strength simultaneous with the increasing of the particle size [11]. These mechanical parameters are lower for composites with larger particles [12] and [13]. The type of resin using in composite plays an important role in increasing the mechanical properties (tensile, bending and shear), noticed by [14] and [15]. Until date, the references about modification of mechanical and morphological properties of lignocellulosic composite because of UV radiation are relatively limited. The aim of the current study is to compare the surface and mechanical properties of lignocellulosic composites before and after ultraviolet exposure.

\section{MATERIALS AND METHODS}

\subsection{Materials}

Two types of composites were studied. The specimens for DMA test were cut from the plates taking into account the recommendation of the European standards for the flexural test by using the method of the three points [16]. The first studied lignocelluloses composite is a commercial one used in automotive industry made from hemp mat and polyurethane resin (RAIGITHANE 8274/RAIGIDUR CREM), with $50 \%$ percentage of reinforcing natural fibres. The second is a new types of composites that contains oak particles with volume fibre fraction of $25 \%$. The oak particles were separated by means of grading sieves according to the criterion of size: wood particles smaller than $0.04 \mathrm{~mm}$, coded L 0.04; wood particles between 0.04 $\mathrm{mm}$ to $0.1 \mathrm{~mm}$, coded L 0.1 ; wood particles between $0.1 \mathrm{~mm}$ to $0.2 \mathrm{~mm}$. coded L 0.2 ; wood particles between $0.2 \mathrm{~mm}$ to $0.4 \mathrm{~mm}$, coded L 0.4 and wood particles between $0.4 \mathrm{~mm}$ to $1 \mathrm{~mm}$, coded L 1.0. The graded fibres were mixed with polyester resin of the POLYLITE 440 - M888 type, using hand lay-up technology. Thus, five different plates were obtained in a molding box, at $22{ }^{\circ} \mathrm{C}$ cure temperature. From these plates the specimens suitable for flexural test have been manufactured with geometry presented in Fig. 1 and physical characteristics in Table 1.

\subsection{Methods}

In the first step, the samples were evaluated from the morphology surfaces using contact angle method and atomic force microscope. Then, the storage and loss modules for different load frequencies were determined by DMA. In the second step, the specimens were exposed to ultra violet (UV) radiation in a radiation chamber and finally, all tests were resumed. The experimental system is presented in Fig. 2.

a) The evaluation of the surface energy of the composite lignocelluloses materials was carried

Table 1. Characteristics of the lignocelluloses composite

\begin{tabular}{lccccc}
\hline Type of samples & Code & Length $l[\mathrm{~mm}]$ & Width $b[\mathrm{~mm}]$ & Thickness $h[\mathrm{~mm}]$ & Weight $m[\mathrm{~g}]$ \\
\hline Hemp fibers & $\mathrm{C} 3$ & 50 & 10.26 & 1.94 & 0.94 \\
\hline \multirow{4}{*}{ Oak particles } & $\mathrm{L} 0.04$ & 50 & 10.28 & 4.14 & 2.47 \\
\cline { 2 - 6 } & $\mathrm{L} 0.10$ & 50 & 10.42 & 4.24 & 2.59 \\
\cline { 2 - 6 } & $\mathrm{L} 0.20$ & 50 & 10.07 & 4.33 & 2.51 \\
\cline { 2 - 6 } & $\mathrm{L} 0.40$ & 50 & 10.11 & 4.62 & 2.67 \\
\hline
\end{tabular}

a)

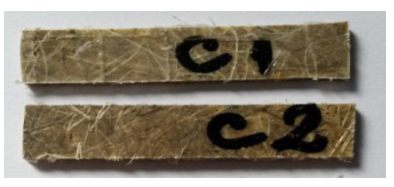

b)

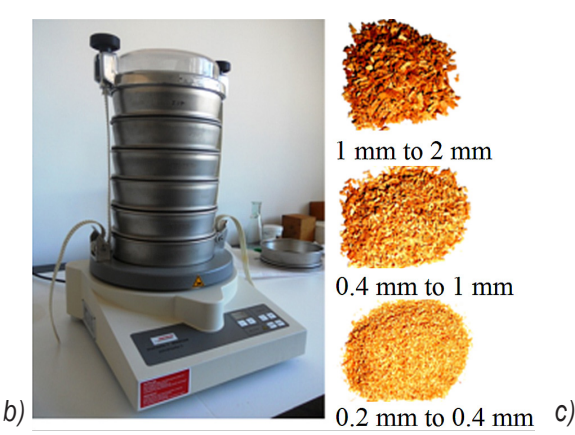

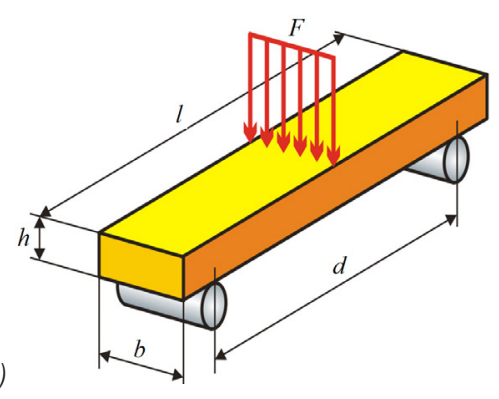

Fig. 1. The samples of lignocelluloses composite: a) hemp fibers reinforcement; $b$ ) different sizes of wood particles; c) a) The geometric shape of the specimens tested DMA ( $l$ length; $d$ distance between supports; $b$ width; $h$ thickness, $F$ applied force) 
out by the $\theta$ contact angle method, which is a thermodynamic equilibrium that is a result of the superficial/ interfacial free energies appearing at the interfaces between two media. The value of the contact angle depends on: the morphology of the substrate expressed by the superficial tension between the solid - gas medium called work of adhesion $W_{A}$ $[\mathrm{mN} / \mathrm{m}]$, the nature of the liquid expressed by the superficial liquid - gas tension $\gamma_{L G}[\mathrm{mN} / \mathrm{m}]$ and the nature of the liquid - substrate interactions expressed by the superficial tension between the solid - liquid medium $\gamma_{S L}[\mathrm{mN} / \mathrm{m}]$, according to the equation YoungDupre, Eq. (1). A liquid placed on a solid surface, in the absence of gravitational forces, will take the shape corresponding to the minimum energy of the system. This occurs when

$$
W_{A}=\gamma_{S L}+\gamma_{L G} \cos \theta,
$$

where $\theta$ contact angle (the angle of the tangent to the liquid-gas surface in the contact point of the liquidsolid interface).

But, the work of adhesion can be calculated with relation Eqs. (2) and (3), being composed by polar component and dispersive component .

$$
\begin{gathered}
W_{A}=\gamma_{S}^{p}+\gamma_{S}^{d}, \\
W_{A}=2 \times \sqrt{\gamma_{L G}^{p} \times \gamma_{S G}^{p}}+2 \times \sqrt{\gamma_{L G}^{d} \times \gamma_{S G}^{d}} .
\end{gathered}
$$

For determination of both components of surface energy (dispersive denoted $U_{d}$ and polar denoted $U_{p}$, in experimental results) using contact angle method, the mathematical system formed by Eqs. (1) and (3) must calculated.

From the point of view of the values of the contact angle, it may take values between $0^{\circ}$ and $180^{\circ}$. If the contact angle $\theta<90^{\circ}$ (polar surface),

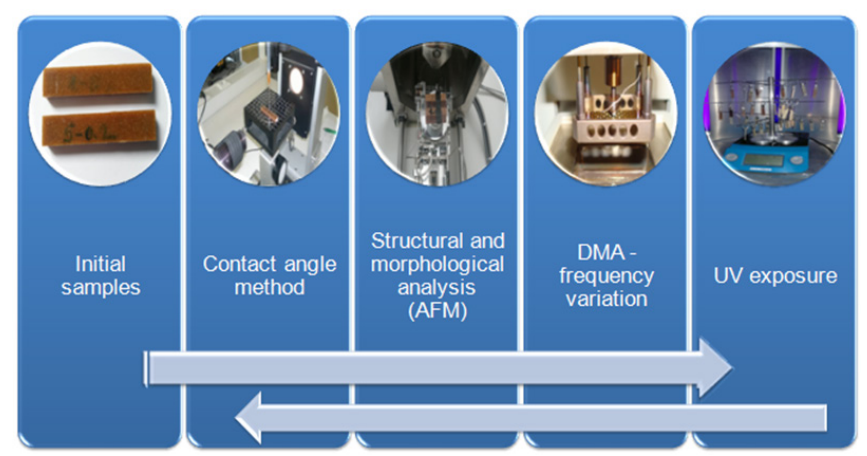

Fig. 2. The measurement of the contact angle

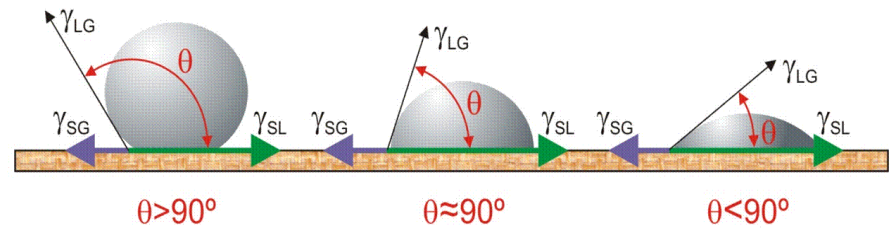

Fig. 3. The measurement of the contact angle

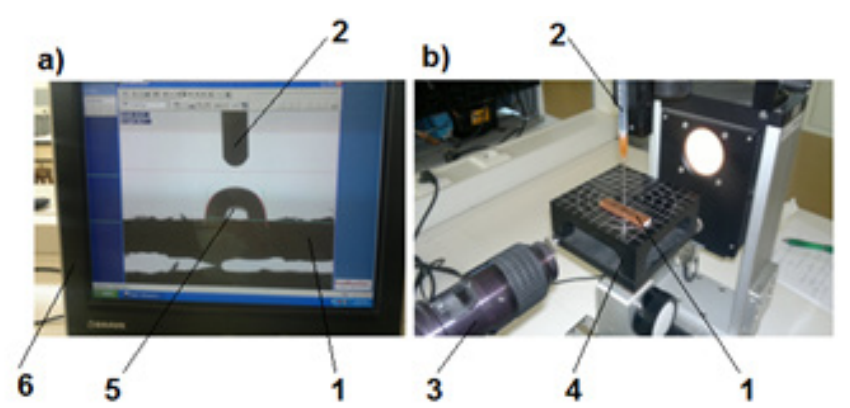

Fig. 4. The experimental determination of the contact angle: a) the projection of the droplet to measure the contact angle; b) the equipment used for contact angle measurement: 1 sample; 2 automatic dosing unit for liquids; 3 high performance video-camera; 4 worktable; 5 the drop profile measured with SCA20 software; 6 software (SCA 20) based on the Young-Laplace equation, which allows to correlate the drop shape with surface tension and with contact angle 
the material is hydrophilic (it absorbs the liquid), and if $\theta>90^{\circ}$ (scattered surface), the material has a hydrophobic character (it does not absorb liquid) (Fig. 3 ). Knowing the $\theta$ angle allows estimating the type of interaction between that surface and the liquid used in the analysis.

The contact angles were measured by the help of the System OCA-20 equipment Data Physics Instruments (Fig. 4a) by using the hanging drop method. Thus, successively a syringe with $\mathrm{H}_{2} \mathrm{O}$ and one with $\mathrm{NaCl}$ were placed on top of all specimens. One drop with a volume of $15 \mu \mathrm{L}$ of sample liquid was dropped from each syringe. By the help of a source of light situated at the back and of a camera placed in front of the droplet the contact between the droplet and the sample was recorded being followed by the measurement of the angle that the droplet forms with the surface of the specimen (Fig. 4b). Dynamic studies for the change of the contact angle offered the possibility of evaluating the absorption/ adsorption capacity of the specimens made of lignocellulosic materials based on the images recorded every second. The analysis for the measuring contact angle was done at the temperature of the room, in normal humidity conditions $\left(T=22.7^{\circ} \mathrm{C}\right.$ and $\left.R H=65 \%\right)$.

b) For the dynamic mechanical analysis and the evaluation of the morphological changes of the surface of samples because of exposure to UV radiation and temperature, rectangular specimens from each category with the physical characteristics shown in Fig. 5 were used. Thus, the complex modulus $E^{*}$, with its two components (the storage modulus $E^{\prime}$ and the loss modulus $\left.E^{\prime \prime}\right)$ were determined under isothermal conditions $\left(T=30^{\circ} \mathrm{C}\right)$, by the variation of the loading frequency $(f=1 \mathrm{~Hz} ; 5 \mathrm{~Hz} ; 10 \mathrm{~Hz} ; 50 \mathrm{~Hz})$.

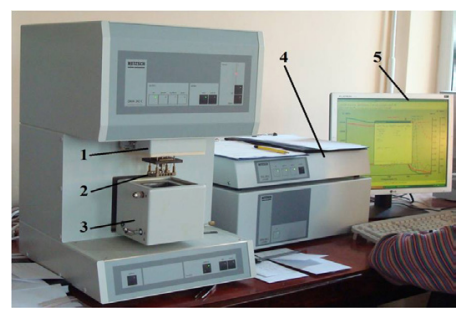

1 the applied force device; 2 the specimen on supports device;

3 the climatic chamber; 4 the acquisition and processing data device; 5 display

Fig. 5. The Netzsch DMA 242 C principle of measurement

c) For the accelerated photolysis process of the specimens, the room with $18 \mathrm{~W}$ Philips fluorescent lamps set apart by $120^{\circ}$ with respect to each other (Fig. 6). The specimens were exposed to UV-A radiations with a wavelength $\lambda$ of $365 \mathrm{~nm}$ for 168 hours ( 7 days), checking every 24 hours the integrity and the clamping to the stand of the specimens. d) The surface morphology of the specimens was measured by the help of the NTEGRA Probe Nanolaboratory, an atomic force microscope (AFM), at the Institute for Research and Development of the Transilvania University of Brasov, in a semi-contact mode, by using a NSG10 cantilever type (NSG10 represents cantilevers series characterized by high resolution noncontact silicon "golden"), at a constant force. Two dimensional (2D) images and histograms were taken and the images of the phase contrast of each sample were analyzed.

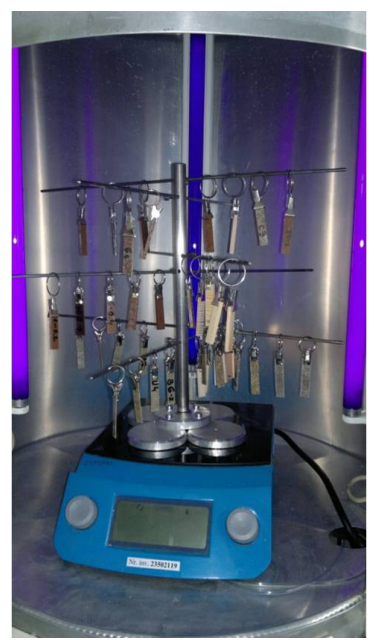

Fig. 6. Accelerated artificial weathering by UV radiations generated by UV fluorescent lamps

\section{RESULTS}

\subsection{Surface Energy}

An important parameter that reflects the surface changes of the composites because of the photolysis is represented by the contact angle of a drop of liquid makes with the surface of the composite. Thus, the absorption/adsorption capacity of the specimens made of lignocelluloses material has been evaluated based on the images recorded every second using as liquid the distilled water and then the $\mathrm{NaCl}$ solution with a concentration of $3.5 \%$. After the measurements, contact angles for each specimen were obtained and the values of the two components of the total surface energy were calculated $U_{\text {tot }}: U_{d}$ the dispersive component and $U_{p}$ the polar component, based on Eqs. (1) and (3) (see cap. 1.2). By summing up the two components, the total surface energy $U_{t o t}$ was obtained. The results are shown in Table 2. 


\subsection{Storage and Loss Modulus}

After the exposure of the specimens to UV radiation, the specimens reinforced with particle of $0.04 \mathrm{~mm}$, $0.1 \mathrm{~mm}, 0.4 \mathrm{~mm}$ and $1 \mathrm{~mm}$ have become more rigid (Table 3).

The increase in stiffness of the polyester composites because of the accelerated weathering represents a specific behavior of the polymeric composites. This trend manifests regardless of the frequency loading. One can notice a different behavior in the case of the composites reinforced with particles of $0.2 \mathrm{~mm}$ in size that manifests a decrease in the storage modulus after UV exposure. A similar behavior was noticed in the polypropylene matrix composites reinforced with wood particles of 0.25 $\mathrm{mm}$ in size. The loss modulus expresses the variation of the viscous behavior of the composites reinforced with wood particles and polyester resin, which is influenced by the rate of the applied frequency (Table 4).

\subsection{Structural and Morphological Changes}

After the exposure to UV radiations, we notice a decrease in the values of the contact angle due to the structural and morphological changes, the analyzed surfaces changing from polar into slightly polar ones. This behavior is confirmed by the topographical evaluation with atomic force microscope which indicates a homogeneous surface of samples before UV exposure compare to increases of surface roughness after artificial ageing.

Table 2. The values of the contact angles and of the surface energy

\begin{tabular}{|c|c|c|c|c|c|c|c|c|c|c|}
\hline \multirow[b]{3}{*}{ Samples } & \multicolumn{4}{|c|}{ Contact angle $\left[{ }^{\circ}\right]$} & \multirow{2}{*}{\multicolumn{2}{|c|}{$\begin{array}{c}\text { Dispersive surface } \\
\text { energy, } U_{d}\end{array}$}} & \multirow{2}{*}{\multicolumn{2}{|c|}{$\begin{array}{c}\text { Polar surface energy, } U_{p} \\
{[\mathrm{mN} / \mathrm{m}]} \\
\end{array}$}} & \multirow{2}{*}{\multicolumn{2}{|c|}{$\begin{array}{c}\text { Total surface energy, } \\
\frac{U_{\text {tot }}=U_{d}+U_{p}}{[\mathrm{mN} / \mathrm{m}]}\end{array}$}} \\
\hline & \multicolumn{2}{|c|}{$\mathrm{H}_{2} \mathrm{O}$} & \multicolumn{2}{|c|}{$\mathrm{NaCl}(3.5 \%)$} & & & & & & \\
\hline & Initial & UV & Initial & UV & Initial & UV & Initial & UV & Initial & UV \\
\hline C3 & $81^{0} \pm 0.5$ & $61^{0} \pm 0.7$ & $75^{\circ} \pm 1.0$ & $74^{0} \pm 2.0$ & 20.29 & 7.54 & 8.94 & 33.00 & 29.22 & 40.54 \\
\hline L 0.04 & $68^{\circ} \pm 1.0$ & $71^{0} \pm 0.3$ & $80^{\circ} \pm 2.0$ & $65^{\circ} \pm 0.6$ & 6.59 & 24.63 & 27.81 & 12.21 & 34.40 & 36.83 \\
\hline L 0.10 & $75^{\circ} \pm 0.3$ & $75^{\circ} \pm 1.0$ & $80^{\circ} \pm 0.6$ & $83^{\circ} \pm 1.0$ & 10.27 & 6.59 & 18.51 & 22.35 & 28.78 & 28.94 \\
\hline L 0.20 & $71^{\circ} \pm 0.6$ & $39^{\circ} \pm 0.5$ & $70^{\circ} \pm 0.5$ & $63^{\circ} \pm 0.6$ & 18.42 & 6.09 & 15.72 & 55.54 & 34.13 & 61.63 \\
\hline L 0.40 & $72^{0} \pm 1.0$ & $48^{\circ} \pm 1.5$ & $75^{\circ} \pm 1.0$ & $69^{\circ} \pm 0.8$ & 13.43 & 5.22 & 18.23 & 49.36 & 31.65 & 54.59 \\
\hline L 1.00 & $72^{0} \pm 0.8$ & $41^{0} \pm 0.6$ & $78^{\circ} \pm 0.8$ & $49^{\circ} \pm 0.7$ & 10.40 & 20.66 & 20.62 & 35.51 & 31.01 & 56.17 \\
\hline
\end{tabular}

Table 3. The mean values of the storage modulus E' measured before and after UV

\begin{tabular}{|c|c|c|c|c|c|c|c|c|c|c|c|c|}
\hline \multirow[b]{2}{*}{ Samples } & \multicolumn{2}{|c|}{$1 \mathrm{~Hz}$} & \multicolumn{2}{|c|}{$5 \mathrm{~Hz}$} & \multicolumn{2}{|c|}{$10 \mathrm{~Hz}$} & \multicolumn{2}{|c|}{$50 \mathrm{~Hz}$} & $1 \mathrm{~Hz}$ & $5 \mathrm{~Hz}$ & $10 \mathrm{~Hz}$ & $50 \mathrm{~Hz}$ \\
\hline & $\begin{array}{c}E^{\prime} \\
{[\mathrm{MPa}]}\end{array}$ & $\begin{array}{l}E_{U V}^{\prime} \\
{[\mathrm{MPa}]}\end{array}$ & $\begin{array}{c}E^{\prime} \\
{[\mathrm{MPa}]}\end{array}$ & $\begin{array}{l}E_{U V}^{\prime} \\
{[\mathrm{MPa}]}\end{array}$ & $\begin{array}{c}E^{\prime} \\
{[\mathrm{MPa}]}\end{array}$ & $\begin{array}{l}E_{U V}^{\prime} \\
{[\mathrm{MPa}]}\end{array}$ & $\begin{array}{c}E^{\prime} \\
{[\mathrm{MPa}]}\end{array}$ & $\begin{array}{l}E_{U V}^{\prime} \\
{[\mathrm{MPa}]}\end{array}$ & \multicolumn{4}{|c|}{$\Delta E^{\prime}=100 \times\left(E_{U V}^{\prime}-E^{\prime}\right) / E^{\prime}[\%]$} \\
\hline $\mathrm{C3}$ & 1152 & 1645 & 1207 & 1711 & 1226 & 1735 & 1255 & 1798 & 42.80 & 41.76 & 41.52 & 43.27 \\
\hline L 0.04 & 3990 & 4025 & 4105 & 4157 & 4223 & 4211 & 4284 & 4351 & 0.88 & 1.27 & -0.28 & 1.56 \\
\hline L 0.10 & 3759 & 4456 & 3936 & 4590 & 4024 & 4645 & 4097 & 4777 & 18.54 & 16.62 & 15.43 & 16.60 \\
\hline L 0.20 & 4249 & 4118 & 4363 & 4248 & 4463 & 4300 & 4527 & 4430 & -3.08 & -2.64 & -3.65 & -2.14 \\
\hline L 0.40 & 3239 & 3419 & 3388 & 3529 & 3413 & 3572 & 3544 & 3689 & 5.56 & 4.16 & 4.66 & 4.09 \\
\hline L 1.00 & 3553 & 3545 & 3672 & 3739 & 3762 & 3806 & 3840 & 3982 & -0.23 & 1.82 & 1.17 & 3.70 \\
\hline
\end{tabular}

Table 4. The mean values of the loss modulus E" measured before and after UV

\begin{tabular}{|c|c|c|c|c|c|c|c|c|c|c|c|c|}
\hline \multirow[b]{2}{*}{ Samples } & \multicolumn{2}{|c|}{$1 \mathrm{~Hz}$} & \multicolumn{2}{|c|}{$5 \mathrm{~Hz}$} & \multicolumn{2}{|c|}{$10 \mathrm{~Hz}$} & \multicolumn{2}{|c|}{$50 \mathrm{~Hz}$} & $1 \mathrm{~Hz}$ & $5 \mathrm{~Hz}$ & $10 \mathrm{~Hz}$ & $50 \mathrm{~Hz}$ \\
\hline & $\begin{array}{c}E^{\prime \prime} \\
{[\mathrm{MPa}]}\end{array}$ & $\begin{array}{l}E^{\prime \prime} U V \\
{[\mathrm{MPa}]}\end{array}$ & $\begin{array}{c}E^{\prime \prime} \\
{[\mathrm{MPa}]}\end{array}$ & $\begin{array}{l}E^{\prime \prime}{ }_{U V} \\
{[\mathrm{MPa}]}\end{array}$ & $\begin{array}{c}E^{\prime \prime} \\
{[\mathrm{MPa}]}\end{array}$ & $\begin{array}{l}E^{\prime \prime} U V \\
{[\mathrm{MPa}]}\end{array}$ & $\begin{array}{c}E^{\prime \prime} \\
{[\mathrm{MPa}]}\end{array}$ & $\begin{array}{l}E^{\prime \prime}{ }_{U V} \\
{[\mathrm{MPa}]}\end{array}$ & \multicolumn{4}{|c|}{$\Delta E^{\prime \prime}=100 \times\left(E_{U V}^{\prime \prime}-E^{\prime \prime}\right) / E^{\prime \prime}[\%]$} \\
\hline C3 & 55 & 82 & 67 & 97 & 78 & 114 & 98 & 139 & 49.09 & 44.78 & 46.15 & 41.84 \\
\hline L 0.04 & 377 & 367 & 361 & 362 & 324 & 380 & 314 & 367 & -2.65 & 0.28 & 17.28 & 16.88 \\
\hline L 0.10 & 338 & 363 & 369 & 365 & 339 & 389 & 312 & 373 & 7.40 & -1.08 & 14.75 & 19.55 \\
\hline L 0.20 & 326 & 390 & 299 & 383 & 287 & 402 & 272 & 380 & 19.63 & 28.09 & 40.07 & 39.71 \\
\hline L 0.40 & 243 & 276 & 258 & 270 & 239 & 288 & 210 & 274 & 13.58 & 4.65 & 20.50 & 30.48 \\
\hline L 1.00 & 289 & 464 & 269 & 445 & 256 & 453 & 256 & 416 & 60.55 & 65.43 & 76.95 & 62.50 \\
\hline
\end{tabular}




\section{DISCUSSION}

The surface energy increased after the exposure to UV radiations (Fig. 7), by changing the contribution of the two components: the value of the polar component $U_{p}$ increased while the value of the dispersant component $U_{d}$ decreased.

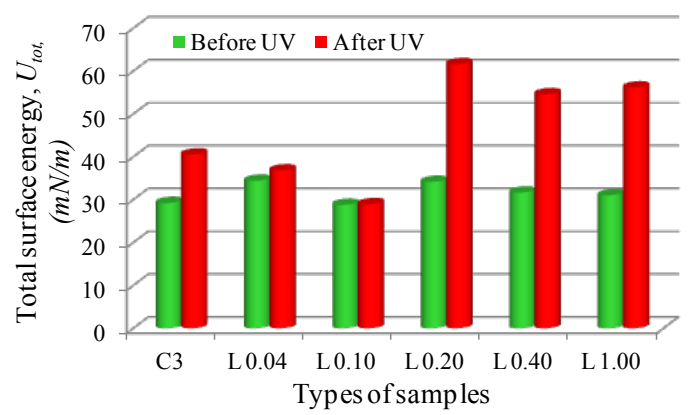

Fig. 7. The variation of the surface energy before and after the artificial weathering

From the point of view of the contact angle and implicit of the surface energy determined with distiller water $\mathrm{H}_{2} \mathrm{O}$ (Fig. 8a), it can be noticed that the UV radiations have influenced the superficial structure of the lignocelluloses composites reinforced with bigger particles (from $0.2 \mathrm{~mm}$ to $1 \mathrm{~mm}$ ). At the same time, the specimens of polyester resin and the wood particles of $0.04 \mathrm{~mm}$ and $0.1 \mathrm{~mm}$ in size were more chemically stable (Fig. 8b). Similarly, one can notice that the material becomes hydrophilic after exposure to ultraviolet radiations, thus increasing the capacity of the lignocelluloses material to absorb liquids, which leads to structural, geometrical and mechanical changes of the material. An exception of overall tendency to decreases of contact angle is recorded in case of sample L 0.04 (an slow increase with $4.41 \%$ for water test) and $\mathrm{L} 0.10$ (3.75\% increase for $\mathrm{NaCl}$ test). In order to stop the phenomenon and implicitly the increase of the life cycle, after the manufacturing

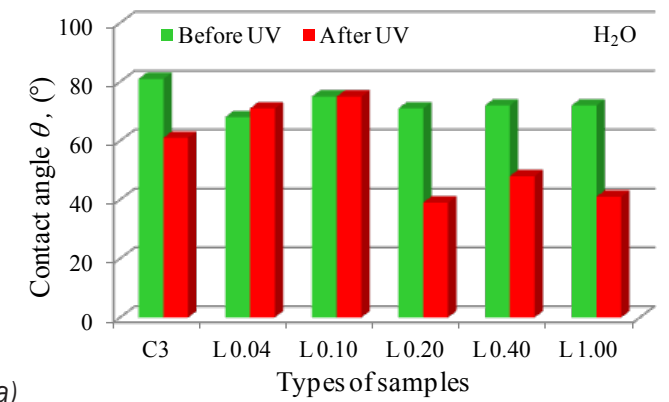

of the specimens a final cross-linking is recommended, which leads to stable chemical bonds between the molecules of the polymer or the use of some additives against UV radiation, as [3] and [10] noticed in the researches. Before UV exposure, the composites reinforced with wood particles have contact angles with values close to the $\mathrm{NaCl}(3.5 \%)$. solution and distilled water $\mathrm{H}_{2} \mathrm{O}$ (Fig. 8). After the exposure to UV radiations, we notice a decrease in the values of the contact angle due to the structural and morphological changes, the analyzed surfaces changing from polar into slightly polar ones.

As far as the contact angle of the surface is concerned when obtained by the sodium chloride solution $\mathrm{NaCl}(3.5 \%)$ we notice its decrease after the exposure to UV, but significant differences of the contact angle measurements are noticeable when obtained with distilled water $\left(\mathrm{H}_{2} \mathrm{O}\right)$.

With the increase of the size of the reinforcing particles, the internal friction in the structure of composites increases after the exposure to UV radiation. The most affected by UV radiation is the composites reinforced with particles of $1 \mathrm{~mm}$, in which case the loss modulus $E$ " increases with almost $60 \%$ to $76 \%$ as can be seen in Table 4 , sample L 1.00 . Between the very small wood particles (of up to $0.04 \mathrm{~mm}$ ), the internal frictions are more reduced after the photolysis of the specimens which can be seen in lower values of viscous modulus after UV exposure.

This can be explained due to the artificial weathering accelerates the cross-linking process of the polyester resin, the very small wood particles being included in polymer chains, the composite having a quasi-homogeneous structure. The larger the particles, the more the deformation energy is dissipated in the matrix and in the reinforcing elements, each of them overtaking a different deformation energy, depending on the viscous-elastic characteristics of the wood particles and of the polyester resin [6] and [10].

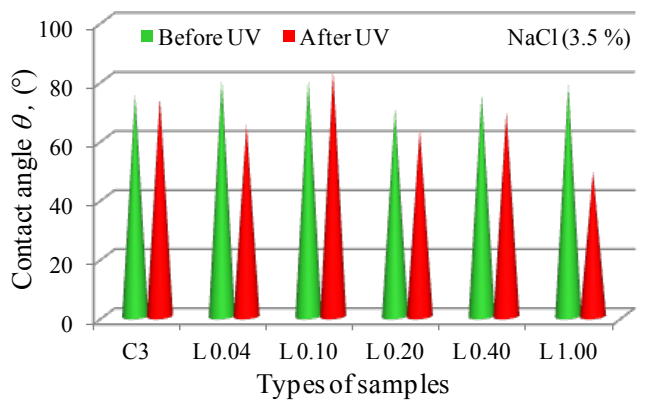

b)

Fig. 8. The variation of the contact angle when indicating the size of the reinforcing particles of the lignocelluloses composites in the case of two liquids: a) $\mathrm{H}_{2} \mathrm{O}$; and b) $\mathrm{NaCl}(3.5 \%)$, before and after exposure to UV radiations 
C3

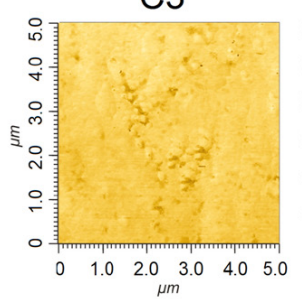

L 0.04
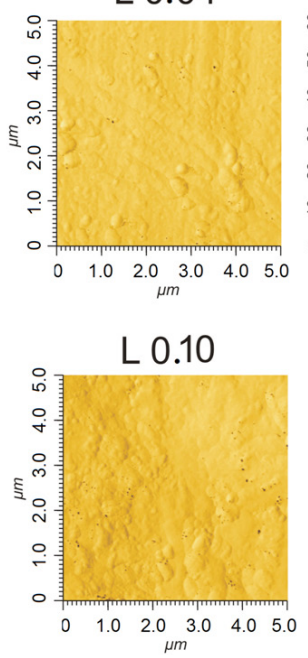

C3 UV
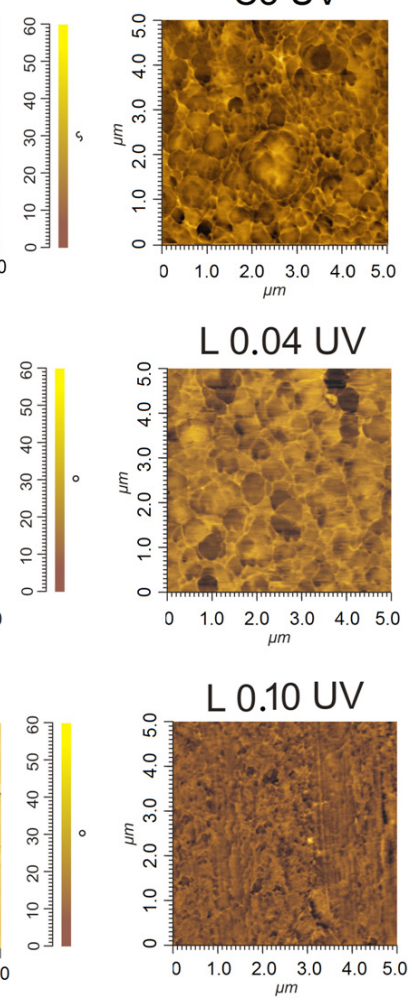

L 0.04 UV
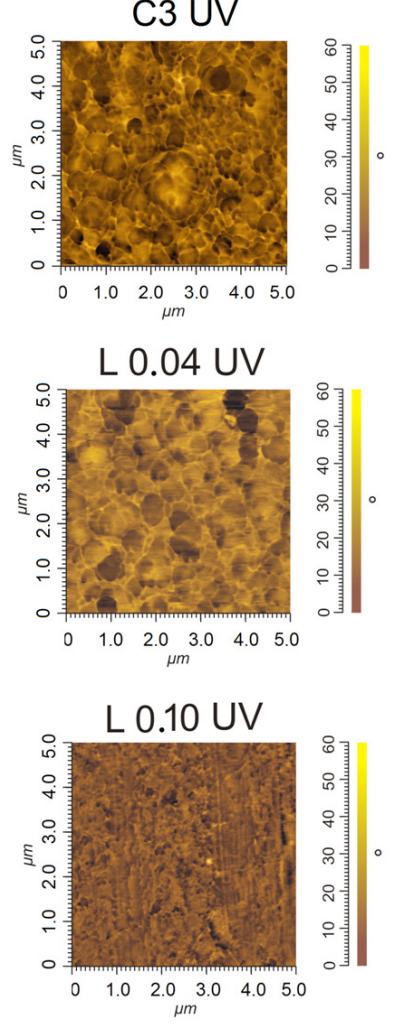

L 0.20

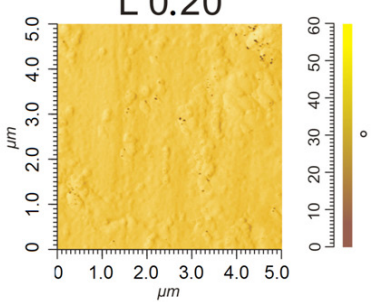

L 0.40
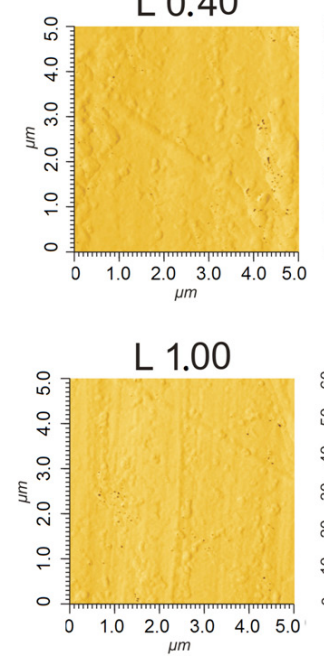
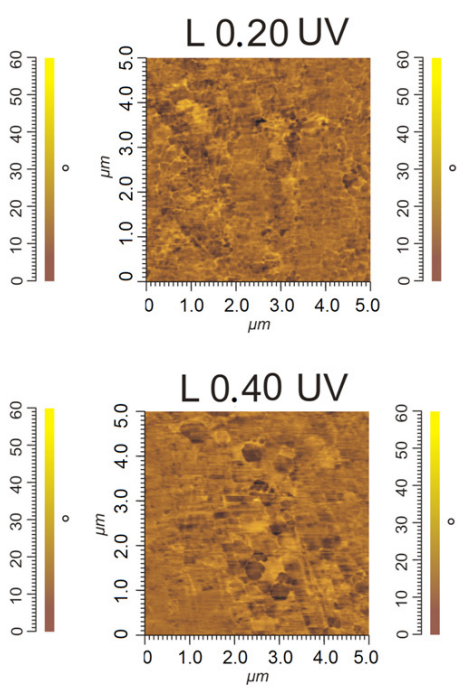

L 0.40 UV

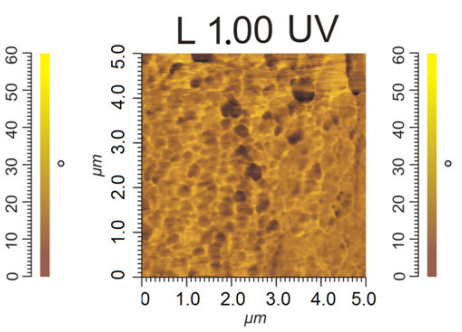

Fig. 9. The phase contrast of different studied samples obtained with AFM

Before the accelerated weathering, in the structure of the lignocelluloses composite there are phenomena specific to wood particles, matrix and interface between matrix and wood particles, which leads to variations of the internal frictions due to the physical connections (of the Van der Waals type) and chemical one situated in various stages of polymerization [14] and [15]. The UV radiation leads to a porous surface due to migration of chemical compounds (Fig. 9). This chemical and physical modification affects in time the rheological behavior of lignocelluloses composite.

From the point of view of roughness, there are two cases (Fig. 10):

a) The first case is that of the surfaces whose roughness increased after the exposure to UV radiations, which shows an oxidative degradation of the respective surfaces. It is the case of the surface of the specimen reinforced with hemp fibres $(\mathrm{C} 1)$, the sample reinforced with wood particles of $0.04 \mathrm{~mm}$ in size (L 0.04) and the solid wood.

b) The second case is that of the surfaces whose roughness decreased after the exposure to UV. Because the decrease in roughness is of tens of nanometers, it can be appreciated that the specimen is morphologically unstable, as is the case of the specimens reinforced with wood particles (L 0.1, L 0.2 and L 0.4).

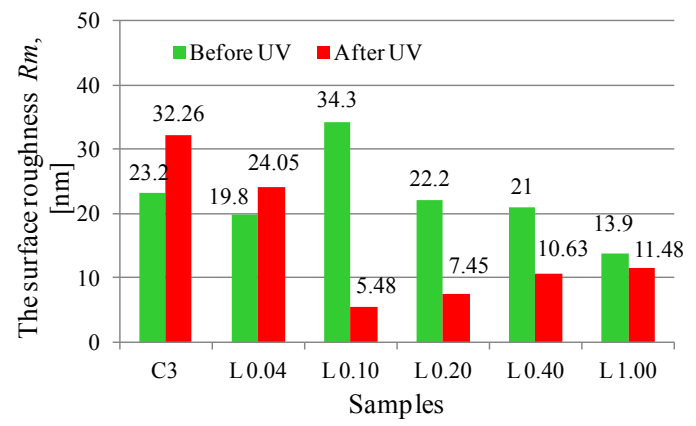

Fig. 10. The variation of surface roughness before and after UV exposure

\section{CONCLUSIONS}

The paper aims to assess structural and morphological changes of lignocelluloses composites surface as UV exposure, using nondestructive methods. Being studied lignocelluloses composites, the determination of structural surface changes due to exposure to UV radiation is very important because cellulose is a 
hydrophilic component. The following conclusions can be drawn from the present work:

- The contact angle method provides the information about surface energy in terms of the capacity of the lignocelluloses material to absorb liquids or to act as a barrier for liquids

- The size and type of lignocelluloses reinforcement in the presence of ultraviolet radiation influence the contribution of the two components of surface energy: the value of the polar component $U_{p}$ increased while the value of the dispersant component $U_{d}$ decreased.

- For the composites reinforced with $0.2 \mathrm{~mm}$ wood particles, the mechanical performance was only slightly affected by the UV radiation in case of presented condition.

- Because the specimens were subjected to bending, extreme stresses develop in the upper and lower strata, and that explains why the influence of the UV radiation is significant due to the crosslinking process of the polymer in the structure of the composite. The hemp reinforced composite presents a similar variation in case of elastic and viscous modulus compare to wood particle reinforced composite which behavior depend by the size of particles.

\section{ACKNOWLEDGEMENTS}

This paper was supported by Program partnership in priority domains - PNIII under the aegis of MCI -UEFISCDI, project no. PN-III-P2-2.1BG-2016-0017/85 SINOPTIC and MECS -ANCS project no. 18060102 .

\section{REFERENCES}

[1] Sahari, J., Sapuan, S.M. (2011). Natural fibre reinforced biodegradable polymer composites. Reviews on Advanced Materials Science, vol. 30, no. 2, p. 166-174.

[2] Han, H. (2015). Study of Agro-composite Hemp/Polypropylene: Treatment of Fibers, Morphological and Mechanical Characterization, PhD thesis, Troyes University of Technology, Troyes.

[3] Belgacem M.N., Gandini A. (2005). The surface modification of cellulose fibres for use as reinforcing elements in composite materials. Composite Interfaces, vol. 12, no. 1-2, p. 41-75, DOI:10.1163/1568554053542188.

[4] Peng, Y., Liu, R, Cao, J. (2013). Effects of Antioxidants on Photodegradation of Wood Flour/Polypropylene Composites during Artificial Weathering. BioResources, vol. 9, no. 4, p. 5817-5830.

[5] Stanciu, M.D., Curtu, I., Groza, M., Savin, A. (2016). The evaluation of rheological properties of composites reinforced with hemp, subjected to photo and thermal degradation. In: Chiru, A., Ispas, N. (eds.) International Congress of Automotive and Transport Engineering, CONAT 2016, Springer, Cham, DOI:10.1007/978-3-319-45447-4_62.

[6] Stanciu, M.D., Bucur, V., Vâlcea, C.S., Savin, A., Sturm, R. (2018). Oak particles size effects on viscous-elastic properties of wood polyester resin composite submitted to ultraviolet radiation. Wood Science and Technology, vo. 52, no.2, p. 365382, D0l:10.1007/s00226-017-0971-0.

[7] Beg, M.D.H., Pickering, K.L. (2008). Accelerated weathering of unbleached and bleached Kraft wood fibre reinforced polypropylene composites. Polymer Degradation and Stability, vol. 93, no. 10, p. 1939-1946, D0l:10.1016/j. polymdegradstab.2008.06.012.

[8] Romanzini, D., Lavoratti, A., Ornaghi Jr, H.L., Amico, S.C., Zattera, A.J. (2013). Influence of fiber content on the mechanical and dynamic mechanical properties of glass/ ramie polymer composites. Materials \& Design, vol. 47, p. 9-15, DOI:10.1016/j.matdes.2012.12.029.

[9] Butylina, S., Hyvärinen, M., Kärki, T. (2012). A study of surface changes of wood-polypropylene composites as the result of exterior weathering. Polymer Degradation and Stability, vol. 97, no. 3, p. 337-345, D0I:10.1016/j. polymdegradstab.2011.12.014.

[10] Azwa, Z.N., Yousif, B.F., Manalo, A.C., Karunasena, W. (2013). A review on the degradability of polymeric composites based on natural fibres. Materials \& Design, vol. 47, p. 424-442, D0l:10.1016/j.matdes.2012.11.025.

[11] Gozdecki, C., Wilczyn, A. (2015). Effects of wood particle size and test specimen size on mechanical and water resistance properties of injected wood-high density polyethylene composite. Wood and Fiber Science, vol. 47, no. 4, p. 365-374.

[12] Benini, K.C.C.C, Voorwald, H.J.C., Cioffi, M.O.H. (2011). Mechanical properties of HIPS/sugarcane bagasse fiber composites after accelerated weathering. Procedia Engineering, vol. 10, p. 3246-3251, D0l:10.1016/j. proeng.2011.04.536.

[13] Pothan, L.A., Oommen, Z., Thomas, S., (2003). Dynamic mechanical analysis of banana fiber reinforced polyester composites. Composites Science and Technology, vol. 63, no. 2, p. 283-293, D0I:10.1016/S0266-3538(02)00254-3.

[14] Athijayamani, A., Ganesamoorthy, R., Loganathan, K.T., Susaiyappan, S. (2016). Modelling and analysis of the mechanical properties of agave sisalana variegata fibre/ vinyl esther composites using box behnken design of response surface methodology. Strojniški vestnik - Journal of Mechanical Engineering, vol. 62, no. 5, p. 273-280, DOl:10.5545/sv-jme.2015.2641.

[15] Croccolo, D., De Agostinis, M., Fini, S., Liverani, A., Marinelli, N., Nisini, E., Olmi, G. (2015). Mechanical characteristics of two environmentally friendly resins reinforced with flax fibres. Strojniški vestnik - Journal of Mechanical Engineering, vol. 61, no. 4, p. 227-236, D0l:10.5545/sv-jme.2014.2248.

[16] ISO 6721-11:2012. Plastics - Determination of Dynamic Mechanical Properties, International Organization for Standardization, Geneva. 